\title{
Cognitive Components Predict Virtual Reality-Induced Analgesia: Repeated Measures in Healthy Subjects
}

OPEN ACCESS

Edited by:

Mel Slater,

University of Barcelona, Spain

Reviewed by:

Tasha Stanton,

University of South Australia,

Australia

Regis Kopper,

Duke University, United States

${ }^{*}$ Correspondence:

Naor Demeter

naor0506@gmail.com

Specialty section: This article was submitted to

Virtual Environments,

a section of the journal

Frontiers in Robotics and Al

Received: 01 August 2017 Accepted: 06 December 2017

Published: 04 January 2018

Citation:

Demeter N, Pud D and Josman N (2018) Cognitive Components Predict Virtual Reality-Induced Analgesia: Repeated Measures in Healthy Subjects.

Front. Robot. Al 4:70. doi: 10.3389/frobt.2017.00070

\author{
Naor Demeter ${ }^{1 *}$, Dorit Pud ${ }^{2}$ and Naomi Josman ${ }^{1}$ \\ ${ }^{1}$ Department of Occupational Therapy, Faculty of Social Welfare \& Health Sciences, University of Haifa, Haifa, Israel, \\ ${ }^{2}$ Faculty of Social Welfare \& Health Sciences, University of Haifa, Haifa, Israel
}

Virtual reality (VR) is an advanced and useful technology in the distraction from pain. The efficacy of VR for reducing pain is well established. Yet, the literature analyzing the unique attributes of VR which impact pain reduction is scarce. The present study evaluated the effect of two VR environments on experimental pain levels. Both VR environments are games used with an EyeToy application which is part of the video capture VR family. The VR environments were analyzed by expert occupational therapists using a method of activity analysis, allowing for a thorough evaluation of the VR activity performance requirements. The VR environments were found to differ in the cognitive load $(\mathrm{CL})$ demands they apply upon subjects. Sixty-two healthy students underwent psychophysical thermal pain tests, followed by exposure to tonic heat stimulation under one of three conditions: Low CL (LCL) VR, high CL (HCL) VR, and control. In addition, following participation in VR, the subjects completed a self-feedback inventory evaluating their experience in $V R$. The results showed significantly greater pain reduction during both VR conditions compared to the control condition $(p=0.001)$. Hierarchical regression revealed cognitive components which were evaluated in the self-feedback inventory to be predictive factors for pain reduction only during the high cognitive load (HCL) VR environment (20.2\%). $\mathrm{CL}$ involved in VR may predict the extent of pain decrease, a finding that should be considered in future clinical and laboratory research.

Keywords: cognitive load, environments, experimental pain, virtual reality, activity analysis

\section{INTRODUCTION}

Distraction is a process in which attention is directed away from the nociceptive stimuli and changes the quality and quantity of pain (Van Damme et al., 2010; Cohen et al., 2014). Distraction can be achieved when attention is directed toward another sensory modality such as visual, auditory, or tactile stimuli (Miron et al., 1989) and is commonly evoked by various cognitive tasks (Eccleston and Crombez, 1999). Few former studies have evaluated the influence of cognitive load (CL) on analgesia, and their findings have been inconsistent. Some studies have shown no interaction between the task load and the nociceptive stimuli (Seminowicz and Davis, 2007). Other evidence shows that the CL

Abbreviations: CL, cognitive load; LCL, low cognitive load; HCL, high cognitive load; CPT, cold pressor test; NPS, numerical pain scale; TSA, thermal sensory analyzer; CPM, conditioned pain modulation. 
involved in the task does impact the level of pain decrease (Miron et al., 1989; Legrain et al., 2002; Buhle and Wager, 2010). This is based on the premise that a task that occupies a person's attention leaves fewer cognitive resources available to focus on the pain (McCaul and Malott, 1984). As an example, Romero et al. (2013) found that higher attentional resources in a task lead to a higher reduction in pain ratings. They found that there is an interaction between the intensity of nociceptive stimuli and the level of perceptual load of a task. Nevertheless, there is also evidence which shows that pain can attract attention; even when the subject does not intend to focus on the pain; its threatening nature withdraws attention (Eccleston and Crombez, 1999; Legrain et al., 2009). Regardless, it is imperative to better understand the link between distraction-induced analgesia and CL.

Virtual reality (VR) is an advanced and useful technology that can be used to distract from pain (Mahrer and Gold, 2009; Kenny and Milling, 2016; Dascal et al., 2017). It is thought that VR distraction is effective because it immerses and engages the person in a way that involves many senses. Therefore, VR requires higher levels of attention (Mahrer and Gold, 2009). VR was shown to be effective in pain relief, both in clinical populations, such as burn pain patients and in laboratory research of healthy subjects (Carrougher et al., 2009; Hoffman et al., 2011); such studies were conducted using diverse methodologies regarding both pain measures and VR paradigms (i.e., Hoffman et al., 2003). However, there is scarce literature examining the specific attribute of VR in reducing pain or relating to the cognitive effort that individuals need to invest in the environment in order to perform the task correctly. Examples of these attributes may be attention, memory, or executive functions. In the VR environments chosen for the current study, attention is needed in order to follow the paddles or light beams presented on the screen. The identification of specific attributes may serve as a key for implementing the approach as part of individualized medicine.

An assessment of the specific attributes of a task can be achieved using a method known as "activity analysis." Activity analysis is one of the earliest tools and a fundamental skill in occupational therapy. This process is a careful observation of an activity, game, or other therapeutic activity. It is intended to assess its features or characteristics for the purpose of identifying and defining the dimensions of the activity performance requirements. It allows for the comparison of activity A with activity B and for the understanding of its therapeutic potential (Kuhaneck et al., 2010; Crepeau et al., 2013; Thomas, 2015). Activity analysis is usually performed by a therapist in order to decide what kind of activity will suit the patient's need; however, it can be performed for research purposes by a few expert judges in the form of a questionnaire in order to decide what the activity requirements and attributes are. As far as we know, activity analysis has yet to be used to analyze VR environment characteristics.

Therefore, the current study aimed to: (1) investigate the effect of participation in two VR environments which differed in terms of CL demand on experimental evoked pain scores in healthy subjects; and (2) identify predictive factors affecting pain reduction during participation in VR.

The study hypotheses were that: (1) a significant reduction in pain ratings will be found following participation in both VR environments in comparison with control condition. (2) Reduction in pain ratings will be significantly greater in the HCL (high cognitive load) environment than in the LCL (low cognitive load) environment. (3) Higher CL in the VR environment will predict pain reduction.

\section{MATERIALS AND METHODS}

The current study is a part of a project that has been divided into two separate publications: (1) the first publication focused on factors of gender and conditioned pain modulation (CPM) as predictors affecting experimental pain stimuli reduction, published in a previous publication (see Demeter et al., 2014). (2) The current study focuses on the CL, addressing comparison to another VR environment. Therefore, the "Materials and Methods" section of this paper resembles our previous publication.

\section{Subjects}

The current study recruited 62 healthy subjects (31 males, 31 females; mean $=24.2, \mathrm{SD}=3.7$ years) aged $18-35$ years. All subjects met the inclusion criteria of being pain free, not taking any medication, and having the ability to communicate and understand all study objectives and instructions. Sample size was calculated based on moderate effect size $f=0.25, \alpha=0.05$, and power $=0.80$. The sample size was set to 48 subjects using $\mathrm{G}^{\star}$ Power software (Faul et al., 2007).

\section{Experimental Pain Models Cold Pressor Test (CPT) - Cold Pain Threshold, Tolerance, and Intensity}

The CPT apparatus (Heto CBN 8-30 Lab equipment, Allerod, Denmark) is a temperature-controlled water bath with a maximum temperature variance of $\pm 0.5 \mathrm{C}$, which is continually stirred by a pump. Subjects were instructed to insert their right hand into the CPT and maintain a static position. After the simultaneous activation of a stopwatch, subjects were asked to keep their hands submerged in the cold water for as long as possible. A cutoff time of $180 \mathrm{~s}$ was set for the purpose of safety. Subjects were requested to indicate the exact point in time in which the cold sensation began to elicit pain. The time until pain was first perceived was defined as time to pain onset (seconds). In the current study, the water temperature of the $\mathrm{CPT}$ was $5^{\circ} \mathrm{C}$. Immediately after hand withdrawal, subjects were asked to indicate their maximal pain intensity on a $0-100$ numerical pain scale (NPS), from 0 which represented "no pain" to 100 which represented the "worst pain one can imagine." The latency of intolerability (spontaneous hand removal) was defined as pain tolerance (seconds). Tolerance for subjects who did not remove their hand from the water for the entire $180 \mathrm{~s}$ was recorded as $180 \mathrm{~s}$.

\section{Thermal Sensory Analyzer (TSA) - Thermal Thresholds and Pain Intensity}

Cold and heat pain thresholds were determined with the limits method on a Medoc TSA-2001 device (Medoc, Israel). A Peltier thermode $(30 \times 30 \mathrm{~mm})$ was attached to the skin above the thenar eminence, and baseline (BL) temperature was set at $32.0^{\circ} \mathrm{C}$ and 
raised or reduced at a rate of $1^{\circ} \mathrm{C} / \mathrm{s}$. The stimulator temperature range was $0-50^{\circ} \mathrm{C}$. Subjects were asked to press a switch when the stimulus was first perceived as painful heat or cold. Three readings were obtained for each thermal modality (cold and hot), and their averages were determined as pain threshold scores. The TSA was also used to determine sensitivity to noxious heat stimulation. Subjects were exposed to tonic heat stimulation $\left(46.5^{\circ} \mathrm{C}\right.$, for $120 \mathrm{~s}$ ) on the medial part of their left ankle and asked to provide feedback on their perception of pain intensity (NPS 0-100).

\section{Assessment of CPM}

Conditioned pain modulation is considered to be a manifestation of pain inhibition and describes a state whereby the response to a given noxious test stimulus is attenuated by another conditioning stimulus that is simultaneously administered to a remote area of the body (Yarnitsky et al., 2010). Phasic heat stimulations were given in order to induce a CPM effect and considered the "test stimulation," whereas cold stimulation was used as a "conditioning” stimulation. For further elaboration, see Demeter et al. (2014).

\section{EyeToy}

The current study included two EyeToy environments. The EyeToy is a popular application from the video capture family, developed by the Sony Corporation for use with a Play-Station 2 platform (www.playstation.com). It is a low cost, off-the shelf game, allowing interaction with virtual objects presented on a standard television screen (Kushner, 2004). The EyeToy presents the user's image in real time, does not require a special environment, and therefore is easy to use in any location (Sveistrup et al., 2003). The user does not wear any equipment during participation in the EyeToy; therefore, he can move freely. The application includes competitive motivational environments allowing the participation of one or more users (Sveistrup et al., 2003). Both of the environments used in the current study were taken from "EyeToy Kinetic" (EyeToy games CD). The environments were chosen because of their similar motor requirements. In the first environment, named "Backlash," the subject is required to move his upper limbs and right leg, to avoid contact with four paddles, two paddles on either side of the screen, with a central circle. In the second environment, named "Equilibrium," the subject is required to move his upper limbs and right leg and be precise in touching light beams appearing on the screen in different positions.

\section{Self-Feedback VR Inventory}

The self-feedback inventory was prepared for the current study and included questions regarding participation in VR based on the Presence Questionnaire and Immersive Tendencies Questionnaire (ITQ) (Witmer and Singer, 1998). Both questionnaires are internally consistent measures with high reliability (Witmer and Singer, 1998). The purpose of the questions was to collect knowledge about the subjective responses of the participants to the VR experience in each environment. The inventory includes a Likert scale of $1-5(1=$ not at all, $5=$ a lot $)$ which evaluates aspects such as: (1) the ability to predict what will happen in response to the subject's action (anticipation); (2) the feeling of skilled movement and interaction with the VR environment (movement skills); (3) the ability to block external distraction and concentrate on a task (attention and cognitive inhibition); and (4) the extent of physical effort demand during a task (physical effort).

\section{Activity Analysis Form}

In order to thoroughly analyze and identify different aspects of each VR environment, "inter-rater reliability" was tested with four experts, using an activity analysis form (Murphy and Davidshofer, 1994). Inter-rater reliability is a process in which two or more raters classify objects into predefined categories, examining the extent to which they agree (Anastasi and Urbina, 1997). Activity analysis is a tool frequently used by occupational therapists for analyzing different activities and identifying the skills and demands of a certain activity. This qualitative-based form includes 73 items which review general aspects of the activity (16 items such as activity description, required preparations, or activity structure) and activity performance components: motor (16 items), sensory (16 items), cognitive (14 items), psychological (19 items), and neuromuscular (8 items). For each item, the experts gave a qualitative evaluation regarding a specific VR environment to which she/he was exposed (Drake, 1991). There was a $100 \%$ agreement between raters on $66 \%$ of the items in LCL and $76.7 \%$ in HCL. For the rest of the items in both LCL and HCL, there was $50-90 \%$ agreement.

\section{Study Procedure Determining VR Environment Characteristics}

Four experienced occupational therapists actively participated in each VR environment and completed the activity analysis form immediately afterward. The occupational therapists were experts in cognitive and motor intervention. Agreement among experts was calculated. According to the experts' evaluation, the main characteristics of each environment were identified and representative titles were given. Specifically, it was found that although both environments were based on a similar motor task, the "equilibrium" environment involved a higher CL and demanded more cognitive resources (attention, accurate movement, and problem solving) compared to the second environment-"backlash." Consequently, the "backlash" VR environment was named low cognitive load virtual reality (LCL), whereas the "equilibrium" environment was named high cognitive load virtual reality (HCL).

\section{Study Design}

Study approval was provided by the Ethical Committee of the University of Haifa, Faculty of Social Welfare \& Health Sciences. Every subject received an explanation of the study, signed an informed consent to participate in the study, and then underwent a set of pain training tests and an introduction to VR environments. After $10 \mathrm{~min}$, a series of pain tests was performed to determine each participant's BL sensitivity to pain. The series of tests included measuring heat and cold pain thresholds (TSA), sensitivity to noxious cold (time to pain onset, tolerance, and intensity), and CPM, as explained above. All tests were conducted in random order with 5-min intervals between them. Immediately thereafter, each subject went through three 
separate experimental conditions in random order: (A) LCL; (B) HCL; or (C) heat stimulation without VR (the control condition). A 5-min break was provided between each study condition. The VR system (Eye-Toy) was turned off during the control condition.

During each condition, subjects were exposed to tonic noxious heat stimulation $\left(46.5^{\circ} \mathrm{C}\right.$, for $\left.140 \mathrm{~s}\right)$ applied to the medial part of the left ankle. Heat pain intensities (NPS 0-100) were reported to be $10,40,70,100$, and $130 \mathrm{~s}$ from the initial heat stimulation, as well as $10 \mathrm{~s}$ after the stimulation was completed, a total of six times. The exposure to each VR environment lasted $120 \mathrm{~s}$ parallel to the heat stimulation, starting $10 \mathrm{~s}$ following the initiation of the heat application (right after the first NPS report). Thus, four NPSs were measured during VR participation. During participation in VR, the user did not wear any equipment except for the peltier thermode which delivered the heat stimuli to their ankle. Immediately after participating in each VR environment, subjects filled out the self-feedback VR inventory, providing feedback regarding their experience in VR as commonly used in other VR studies (Kizony et al., 2006).

\section{Statistical Analyses}

Descriptive statistics described subjects and study variables. Repeated measure ANOVA was performed to explore the differences in the extent of pain decrease between the three study conditions. In order to examine differences between six measurements, a Bonferroni post hoc test was performed. Repeated contrast was conducted in order to examine the interaction effect. The maximal pain decrease from BL was calculated for each study condition separately (i.e., $\Delta \mathrm{LCL}, \Delta \mathrm{HCL}$, and $\Delta$ Control). A Spearman correlation test examined correlations between all pain measurers taken before the three study conditions and pain decrease following VR. Hierarchical regression was used to examine the variables predicting pain decrease following VR. Results were considered significant at the 0.05 level and presented as mean \pm SEM.

\section{RESULTS}

All the pain measures that were taken before the three study conditions are depicted in Table 1.

The mean $( \pm$ SEM) scores of the self-feedback VR inventory (1-5) were as follows: (1) following LCL: anticipation, $3.8 \pm 0.91$; movement skills, $3.9 \pm 0.80$; attention and cognitive inhibition, $4.2 \pm 0.64$; physical effort, $3 \pm 0.87$; (2) following HCL: anticipation, $3.3 \pm 1.11$; movement skills, $3.1 \pm 0.92$; attention and cognitive inhibition, $4.1 \pm 0.85$; and physical effort, $1.8 \pm 0.85$. Significant differences between the two VR environments were found; in the LCL VR environment, the subjects reported that they could better anticipate what would happen in response to their action, that they felt more skilled in movement, and that the activity had a higher physical effort demand (Figure 1).

\section{Effect of VR Participation on Pain Intensity-Within-Session Results LCL Environment}

The mean BL heat pain score taken before exposure to VR was $63.6 \pm 3.3 ; 30 \mathrm{~s}$ after the heat stimulus was administered, the mean pain score dropped to $32.8 \pm 3$ (test 1 ), $29.0 \pm 2.7$ (test 2), $30.0 \pm 2.9$ (test 3 ), and $33.0 \pm 3.2$ (test 4 ). In the last heat measurement following $120 \mathrm{~s}$ from the beginning of the stimulation and right after VR was discontinued (test 5), the mean pain score increased to $47.8 \pm 3.5$ [RM ANOVA, $F(5,305)=73.54, p<0.001, \eta^{2}=0.55$ ] Bonferroni test revealed that in the LCL environment, all pain measurements (tests $1,2,3,4$, and 5) were significantly different compared with BL measurement $(p<0.001)$.

\section{HCL Environment}

The mean BL heat pain score taken before exposure to VR was $65.6 \pm 3.3 ; 30 \mathrm{~s}$ after the heat stimulus was administered, the mean pain score dropped to $33.2 \pm 24.9$ (test 1), $32.7 \pm 3.2$ (test 2), $35.4 \pm 3.6$ (test 3 ), and $33.6 \pm 3.6$ (test 4 ). In the last heat measurement, $120 \mathrm{~s}$ from the beginning of the stimulation and right after VR was discontinued (test 5), the mean pain score increased to $45.4 \pm 3.9$ [RM ANOVA, $F(5,305)=58.92, p<0.001, \eta^{2}=0.49$ ] Bonferroni test revealed that in HCL environment, all pain measurements (tests $1,2,3,4,5)$ were significantly different compared with BL measurement $(p<0.001)$.

\section{Control Session}

The mean BL heat pain score was $63.9 \pm 3.2$, which decreased to $48.4 \pm 3.2$ at test 1 [RM ANOVA, $F(5,305)=17.26, p<0.001$, $\left.\eta^{2}=0.22\right]$. During this session, across the following four measurements, pain ratings were similar: $48.0 \pm 3.3,52.6 \pm 3.5,56.4 \pm 3.7$, and $55.3 \pm 4$ (tests 2, 3, 4, and 5 respectively). Bonferroni test revealed that in the control group, all pain measurements (tests $1,2,3$, and 4 ) were significantly different than BL measurement $(p<0.001)$, except the last measurement (test 5) which was not significantly different than BL.

The maximal pain reduction was found to be between test 1 (BL) and test 3. Therefore, the difference between these two measures was calculated and the value, named $\Delta \mathrm{VR}(\Delta \mathrm{LCL}=\Delta$ low cognitive load VR), $\Delta \mathrm{HCL}=(\Delta$ high cognitive load VR $)$, was used for further statistical analyses.

\section{Effect of VR Participation on Pain Intensity-Sessions Comparison}

No significant differences were identified between the three pain scores at BL [RM ANOVA, $F(2,122)=0.64, p=0.53$ ]. However,

TABLE 1 | Descriptive values of pain parameters examined before the study conditions.

\begin{tabular}{|c|c|c|c|c|c|c|c|}
\hline & $\begin{array}{l}\text { Heat pain } \\
\text { intensity }\end{array}$ & $\begin{array}{l}\text { Cold pain } \\
\text { intensity }\end{array}$ & Cold tolerance (s) & Cold threshold (s) & Cold threshold $\left({ }^{\circ} \mathrm{C}\right)$ & Heat threshold $\left({ }^{\circ} \mathrm{C}\right)$ & $\begin{array}{l}\text { Conditioned pain } \\
\text { modulation }\end{array}$ \\
\hline Mean \pm SEM & $51.6 \pm 3.7$ & $83.4 \pm 1.7$ & $33.8 \pm 5.2$ & $4.9 \pm 0.4$ & $9.3 \pm 0.9$ & $46.5 \pm 0.4$ & $28.9 \pm 2.4$ \\
\hline Median & 53.5 & 85 & 20.5 & 4.0 & 8. 6 & 47.6 & 25 \\
\hline Range & $0-100$ & $40-100$ & $6-180$ & $1-19$ & $0.3-25.6$ & $36.9-50$ & $0-70$ \\
\hline
\end{tabular}




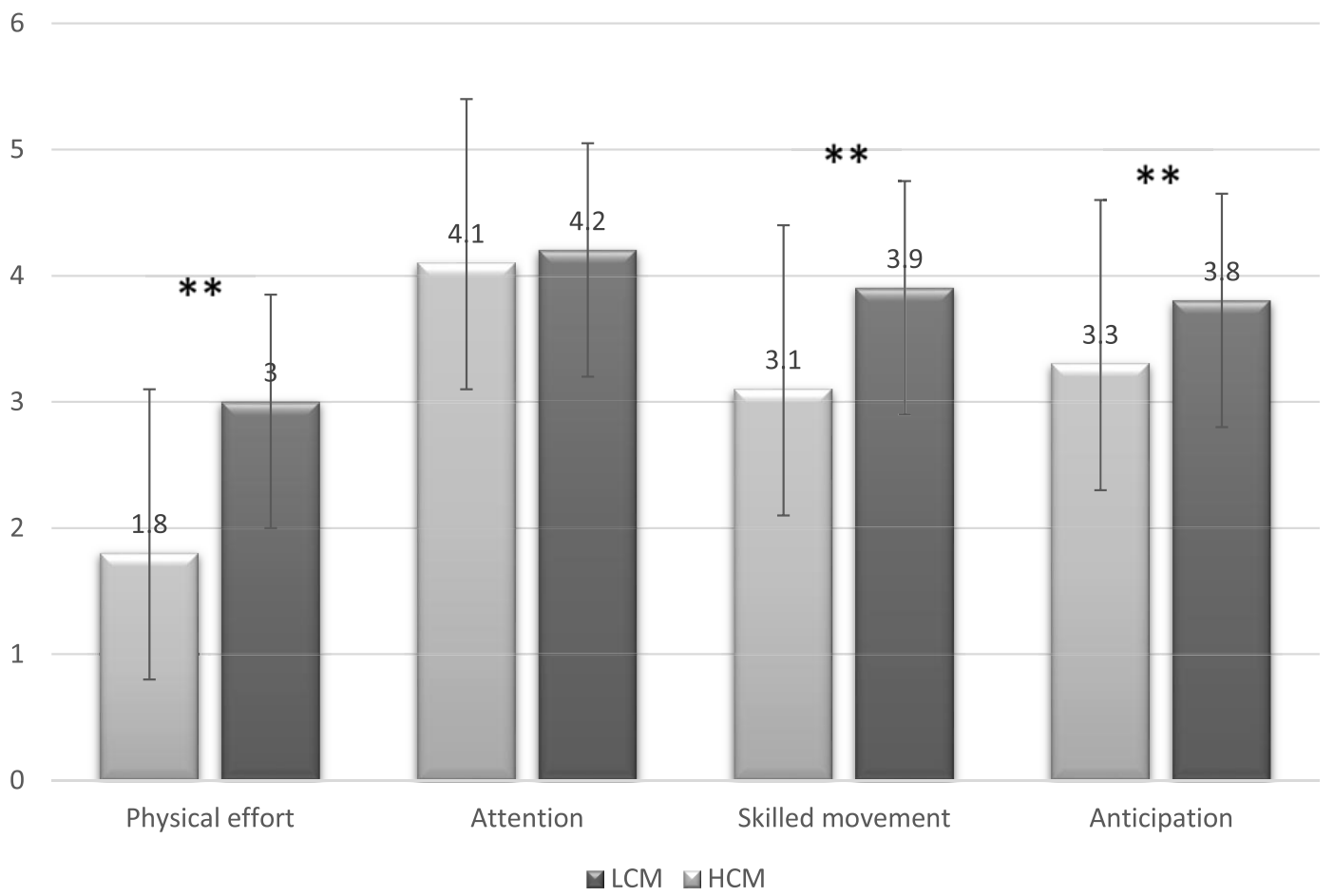

FIGURE 1 | Self-Feedback virtual reality inventory (mean \pm SD) (scale 1-5; 1: not at all and 5: very much).

the reduction in pain intensity across the entire $140 \mathrm{~s}$ was significantly different between the study conditions $[F(10,610)=14.53$, $\left.p<0.001, \eta^{2}=0.19\right]$. Repeated contrast tests showed a significantly greater reduction in pain in VR conditions compared with control conditions between $\mathrm{BL}$ and test $1[F(2,183)=14.97$, $\left.p<0.001, \eta^{2}=0.14\right]$. In addition, there was a significant increase in pain ratings in test 5 in VR conditions only $[F(2,183)=21.92$, $\left.p<0.001, \eta^{2}=0.19\right]$ (Figures 2 and 3).

\section{Correlations between the Battery of Pain Measures and Maximal Pain Decrease in the Three Study Conditions}

In the LCL environment, the Spearman test resulted in a negative correlation between $\Delta \mathrm{LCL}$ and heat pain threshold $(r=-0.27$, $p=0.03$ ) and a positive correlation with heat pain intensity $(r=0.33, p=0.01)$. In addition, a positive correlation was found between $\Delta \mathrm{LCL}$ and CPM $(r=0.39, p=0.002)$. In the HCL environment, only one correlation was found to be significant; this was between $\Delta \mathrm{HCL}$ and CPM $(r=0.40, p=0.001)$. All other correlations were not found to be significant. In the control condition, no significant correlations were found between $\Delta$ control and battery of pain measures.

\section{Regression Analyses}

Hierarchical regression analysis was conducted for each of the study conditions in order to identify predictive variables for pain reduction. The following variables were examined as possible predictors: gender, all pain measures, and four statements of the self-feedback VR inventory (anticipation, movement skills, attention and cognitive inhibition, and physical effort). In the LCL condition, hierarchical regression showed that $6.1 \%$ of the pain decrease variance was explained by gender, meaning that pain decreased more in men than in women. CPM accounted for another $7.5 \%$ of the explained variance, indicating that the extent of CPM predicted pain decrease (Table 2).

Hierarchical regression showed that gender predicted $10 \%$ of the explained variance in the HCL condition, as well, meaning that pain was less decreased in women than in men. CPM predicted $11.6 \%$ of the variance, meaning that the extent of CPM predicted decrease in pain. In addition, two statements of the self-feedback inventory (anticipation + attention and cognitive inhibition) added another $20.2 \%$ of the explained variance, meaning that the higher the score for abilities of anticipation, attention and cognitive inhibition, the more the pain decreased (Table 3 ).

No predictive variables were identified in the control condition $[F(4,56)=1.89, p=0.13]$.

\section{DISCUSSION}

The current study had three hypotheses, of which only the following two were supported in the study: (1) during VR with two different CL tasks, pain ratings were significantly reduced with no difference in the extent of reduction between the two virtual environments; (3) attention and cognitive inhibition, as well as anticipation, predicted pain reduction in the HCL environment only (Demeter et al., 2016). The second hypothesis was not supported: (2) reduction in pain ratings will be significantly greater 


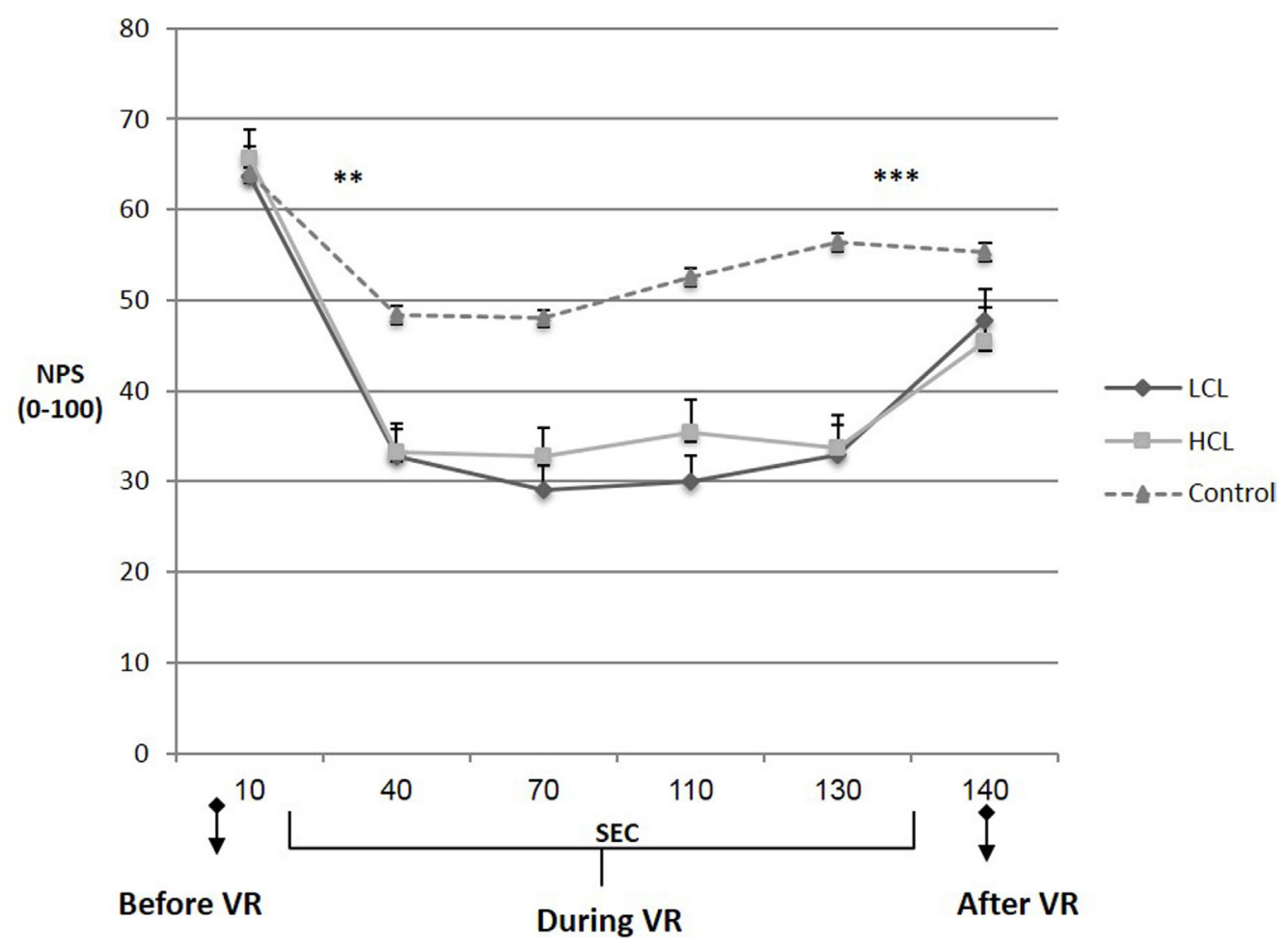

FIGURE 2 | Heat pain intensity during three study conditions (mean \pm SEM). Asterisks represent differences between the two virtual reality (VR) conditions and control within two adjacent time points. LCL, low cognitive load VR; HCL, high cognitive load VR. ${ }^{* *} p<0.01,{ }^{* \star *} p<0.001$.

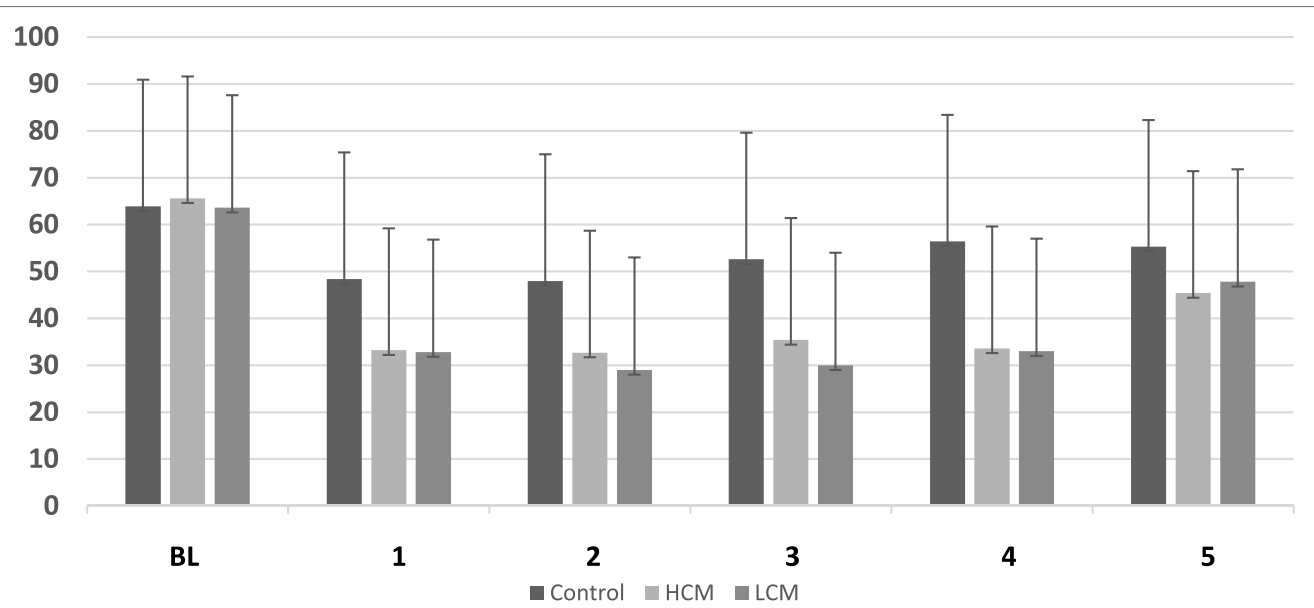

FIGURE 3 | Pain intensity measurements (mean \pm SD) of six pain scores in three study conditions.

in the HCL (high cognitive load) environment than in LCL (low cognitive load) environment.

Virtual reality has been shown to be effective as a pain relief technique in a variety of clinical pain conditions (i.e., Hoffman et al., 2004; Dascal et al., 2017) and in the laboratory setting, demonstrating its alleviating effect on experimental evoked pain (i.e., Hoffman et al., 2003; Sil et al., 2014). Yet, the data examining the VR environment attributes that impact pain reduction are limited. One study compared the effects of two different environments (warm and cold) on thermal pain intensities in healthy volunteers (Mulhberger et al., 2007). The authors hypothesized that a cold environment would reduce heat pain and vice versa. Nevertheless, this hypothesis was refuted when no differences were found in the effect of each environment on pain in both models. Law et al. (2010) examined whether a higher level of central cognitive processing demand (e.g., working memory and 
emotional control) involved in a distraction task would increase tolerance for cold pressor pain. They compared interactive versus passive distraction tasks via a VR-type helmet and demonstrated that the effect of distraction on cold pain tolerance was significantly enhanced when the distraction task included greater demands for central cognitive processing. Loreto-Quijada et al. (2014) compared the effects of two VR environments on a set of pain-related and cognitive variables. One aimed to distract attention away from pain (VRD), and the other was designed to enhance pain control (VRC). It was shown that the VRD intervention significantly raised the pain threshold and increased pain tolerance, while VRC seems to have a greater effect on the cognitive variables, such as the negative thoughts that commonly accompany pain problems. The current study presented in this article focused only on VR environments that aimed to distract attention away from pain and showed similar results for pain reduction; as mentioned, pain intensity was reduced during both VR environments.

The fact that the settings of these laboratory studies are diverse in many aspects points to the barriers that limit the generalization of conclusions among different studies. The current study adds that participation in VR reduces experimental pain intensity regardless of a specific cognitive demand environment. While the fact that VR is an efficient pain distracter is not novel, the similarity of those two chosen environments in their ability to reduce pain was surprising. We believe that although a distinction in the CL between the two tasks was verified, the CL per se was not distinguished enough in this study. When the VR environments were first chosen, we wished to minimize bias as much as possible by choosing similar tasks through the means of general presentation and motor activity. Even though the main parameter that was identified as diverse was the amount of CL involved, it

TABLE 2 | Hierarchical regression for predicting variables of pain decrease in an LCL environment.

\begin{tabular}{|c|c|c|c|c|c|c|}
\hline \multirow[b]{2}{*}{ Variable } & \multicolumn{3}{|c|}{ Model 1} & \multicolumn{3}{|c|}{ Model 2} \\
\hline & B & SE $B$ & $\beta$ & B & SE $B$ & $\beta$ \\
\hline Gender & 9.21 & 4.70 & $0.25^{\star}$ & 6.53 & 4.70 & 0.18 \\
\hline Conditioned pain modulation & & 0.061 & & 0.29 & $\begin{array}{l}0.13 \\
0.136\end{array}$ & $0.28^{\star}$ \\
\hline$F$ for change in $R^{2}$ & & $3.84^{*}$ & & & $5.01^{*}$ & \\
\hline
\end{tabular}

${ }^{*} p \leq 0.05$. could be that the variation between environments was not sharp enough. Therefore, no difference in their impact on pain was found. Hence, the contribution of the CL on pain reduction as was shown in previous studies (Eccleston and Crombez, 1999) cannot be ruled out due to the negative results of the present study; further studies are therefore warranted in order to answer this issue.

The present study also identified predictive factors affecting pain reduction during VR. Three predictors were identified. The first two predictors, including gender and CPM are discussed in a previous publication (see Demeter et al., 2014). The previous publication (Demeter et al., 2014) included the same sample of subjects, while the current research examined another VR condition. The last and best predictor identified in this study as an efficient pain reducer under VR included the following cognitive components: (1) attention and cognitive inhibition and (2) anticipation. These cognitive components made an impact only when a high cognitive effort was required within the HCL VR environment.

The link between pain and cognitive performance has been previously observed in experimental and clinical settings (i.e., Coen et al., 2008), and the findings are inconsistent. Attention constitutes the most studied cognitive component in relation to pain. Evidence shows that while attending to a painful stimulus generally increases perceived intensity (Van Damme et al., 2010); previous studies have found that only a sufficiently attention-demanding cognitive task can shift attention away from pain (Eccleston and Crombez, 1999). Moreover, some evidence shows that pain can attract attention, causing the subject to put his focus on the pain stimuli rather than being distracted from the pain (Legrain et al., 2009). The current study identified not only attention but also cognitive inhibition and anticipation as possible predictors for pain reduction during a task with a high cognitive load. Cognitive inhibition represents the ability to suppress irrelevant information and is considered a component of executive functions. Other components of executive functions include the ability to formulate and maintain goals and strategies and to retain information for further processing (Connor and Maeir, 2011). To the best of our knowledge, there is sparse evidence relating to the link between executive functions and pain inhibitory control. One review (Solberg Nes et al., 2009) has proposed a relationship between self-regulation, a component of executive functions, and the ability to cope and manage different aspects of chronic pain conditions. Although it is important and

TABLE 3 | Hierarchical regression for predicting variables of pain decrease in an HCL environment.

\begin{tabular}{|c|c|c|c|c|c|c|c|c|c|}
\hline \multirow[b]{2}{*}{ Variable } & \multicolumn{3}{|c|}{ Model 1} & \multicolumn{3}{|c|}{ Model 2} & \multicolumn{3}{|c|}{ Model 3} \\
\hline & B & SE $B$ & $\boldsymbol{\beta}$ & B & SE $B$ & $\boldsymbol{\beta}$ & B & SE $B$ & $\boldsymbol{\beta}$ \\
\hline Gender & 14.33 & 5.65 & $0.31^{*}$ & 10.24 & 5.51 & 0.22 & 14 & 5 & $0.31^{\star \star}$ \\
\hline Conditioned pain modulation & & & & 0.44 & 0.15 & $0.35^{\star *}$ & 0.33 & 0.14 & $0.27^{\star}$ \\
\hline $\mathrm{A}+\mathrm{Cl}$ an ant & & & & & & & 10.91 & 2.9 & $0.4^{\star \star \star}$ \\
\hline$R^{2}$ & & 0.10 & & & 0.21 & & & 41.2 & \\
\hline$F$ for change in $R^{2}$ & & $6.42^{\star}$ & & & $7.88^{\star \star}$ & & & $9.95^{\star \star \star}$ & \\
\hline
\end{tabular}

${ }^{*} p<0.05{ }^{* *} p<0.01{ }^{* * *} p<0.001$.

CPM, conditioned pain modulation; $A+C l$, attention + cognitive inhibition; ant, anticipation. 
adds knowledge about the cognitive aspect, it focuses on studies of patients with chronic pain, unlike the current study which involved experimental pain in healthy subjects. Another study evaluated these links with healthy volunteers exposed to a cold pain model (Oosterman et al., 2010); better cognitive inhibition (as measured by the Stroop test), but not other executive functions, were found to be associated with less sensitivity to pain. Similarly, the current study obtained evidence that high perceived cognitive inhibition, as reported by the participant, predicted pain reduction.

Anticipation of action is another executive function component (Barkley, 1997). When a task is performed repeatedly, it is more likely to be automatically processed, which in turn reduces the accompanying CL. This renders the task less effective in competing with pain for attention resources (Eccleston and Crombez, 1999). This study revealed, using the selffeedback VR inventory, that the more the subjects participated in the VR environment, the more they reported an ability to more accurately anticipate the outcomes of their action. Thus, when a subject anticipated the outcome of his actions, he or she was less distracted from pain. There was a significant difference between the two VR environments in the extent of anticipation. In the HCL environment, subjects reported that they were less able to anticipate the result of their action. This finding further supports the notion that the HCL environment has a higher cognitive load. However, the lack of significant difference between the environments in the extent of attention needed by the subjects may explain the lack of difference in pain reduction between the two VR environments.

The uniqueness of the current study also derives from the use of the "activity analysis" method for analyzing the VR environments' task requirements. This process, which is usually used by occupational therapists, allows the practitioner to understand the demands placed upon a person who engages in a certain task (Thomas, 2015) and can also be used for research purposes. Based on our literature review, the current study is the first to compare VR attributes using activity analysis.

\section{Study Limitations}

The activity analysis is a basic efficient tool used by occupational therapists. However, to the best of our knowledge, it was never used before for detecting general differences between VR environments and specifically differences in CL. Therefore, further

\section{REFERENCES}

Anastasi, A., and Urbina, S. (1997). Psychological Testing, 7th Edn. Upper Saddle River: Prentice Hall.

Barkley, R. A. (1997). Behavioral inhibition, sustained attention, and executive functions: constructing a unifying theory of ADHD. Psychol. Bull. 121, 65-94. doi:10.1037/0033-2909.121.1.65

Buhle, J., and Wager, T. D. (2010). Performance-dependent inhibition of pain by an executive working memory task. Pain 149, 19-26. doi:10.1016/j. pain.2009.10.027

Carrougher, G. J., Hoffman, H. G., Nakamura, D., Lezotte, D., Soltani, M., Leahy, L., et al. (2009). The effect virtual reality on pain and range of motion in adults with burn injuries. J. Burn Care Res. 30, 785-791. doi:10.1097/ BCR.0b013e3181b485d3 validation and future research are recommended for evaluating the activity analysis together with objective experimental measures of the effect of CL. Previous evidence (i.e., Pud et al., 2009) shows that sensitivity to pain may be affected by hand dominancy. The current study did not evaluate hand dominancy, and it is recommended to address the issue in future studies. In addition, the subjective experience of the subject in the VR environment was evaluated by the Self-Feedback VR Inventory which included only a few questions taken from the presence and ITQ (Witmer and Singer, 1998). Non-use of these questionnaires as a whole may affect their reliability.

In conclusion, this novel study identified evidence for significant pain reduction during submersion in two VR environments. This aspect needs to be considered when customizing pain treatment protocols for patients coping with pain. Further work is necessary in order to assess the benefits of CL in pain reduction.

\section{ETHICS STATEMENT}

The study was approved and carried out in accordance with the recommendations of "the Ethical Committee of the University of Haifa, Faculty of Social Welfare \& Health Sciences"; with written informed consent from all subjects. The protocol was approved by "the Ethical Committee of the University of Haifa, Faculty of Social Welfare \& Health Sciences” (approval number-092/10).

\section{AUTHOR CONTRIBUTIONS}

All authors of this article (ND, DP, and NJ) have substantially contributed to the conception of the work, its analysis, and interpretation of data and have approved the publication of this work.

\section{ACKNOWLEDGMENTS}

This study was supported by a grant from the Dean of the Faculty of Social Welfare and Health Sciences, University of Haifa, Israel, for interdisciplinary research. Part of this study was submitted by the first author to the University of Haifa, Department of Occupational Therapy in partial fulfillment of the requirement for the master's degree. The current article was elaborated based on a previous publication published in the proceeding book of the 11th Intl Conf. Disability, Virtual Reality \& Associated Technologies, Los Angeles, CA, USA, 20-22 September 2016.

Coen, S. J., Aziz, Q., Yaguez, L., Brammer, M., Williams, S. C., and Gregory, L. J. (2008). Effects of attention on visceral stimulus intensity encoding in the male human brain. Gastroenterology 135, 2065-2074. doi:10.1053/j. gastro.2008.08.005

Cohen, L. L., Cousins, L. A., and Martin, S. R. (2014). "Procedural pain distraction," in Oxford Textbook of Paediatric Pain, 1st Edn, eds P. J. McGrath, B. J. Stevens, S. M. Walker, and W. T. Zempsky (Oxford, UK: Oxford University Press), 553-559.

Connor, L. T., and Maeir, A. (2011). Putting executive performance in a theoretical context. OTJR (Thorofare N. J.) 31, S3-S7. doi:10.3928/15394492-20101108-02

Crepeau, E. B., Cohn, E. S., and Boyt Schell, B. A. (2013). "Analyzing occupations and activity," in Willard \& Spackman's Occupational Therapy, 12th Edn, eds E. B. Crepeau and B. A. Boyt Schell (Philadelphia: Lippincott Willams \& Wilkins), 359-386. 
Dascal, J., Reid, M., IsHak, W. W., Spiegel, B., Recacho, J., Rosen, B., et al. (2017). Virtual reality and medical inpatients: a systematic review of randomized, controlled trials. Innov. Clin. Neurosci. 14, 14-21.

Demeter, N., Josman, N., Eisenberg, E., and Pud, D. (2014). Who can benefit from virtual reality to reduce experimental pain? A crossover study in healthy subjects. Eur. J. Pain 19, 1467-1475. doi:10.1002/ejp.678

Demeter, N., Pud, D., and Josman, N. (2016). "Experimental pain reduction in two different virtual reality environments: a crossover study in healthy subjects," in The $11^{\text {th }}$ International Conference on Disability, Virtual Reality and Associated Technologies, eds P. Sharkey and S. Rizzo (Los Angeles, CA: Paper Presented at ICDVRAT 2016), 165.

Drake, M. (1991). "Completed activity analysis," in Crafts in Therapy and Rehabilitation, ed. M. Drake (New Jersey: SLACK), 199-205.

Eccleston, C., and Crombez, G. (1999). Pain demands attention: a cognitive affective model of the interruptive function of pain. Psychol. Bull. 125, 356-366. doi:10.1037/0033-2909.125.3.356

Faul, F., Erdfelder, E., Lang, A.-G., and Buchner, A. (2007). G*Power 3: A flexible statistical power analysis program for the social, behavioral, and biomedical sciences. Behav. Res. Methods 39, 175-191.

Hoffman, H. G., Chambers, G. T., Meyer, W. J., Araceneaux, L. L., Russell, W. J., Seibel, E. J., et al. (2011). Virtual reality as an adjunctive non-pharmacologic analgesic for acute burn pain during medical procedures. Ann. Behav. Med. 41, 183-191. doi:10.1007/s12160-010-9248-7

Hoffman, H. G., Garcia-Palacios, A., Kapa, V. A., Beecher, J., and Sharar, S. R. (2003). Immersive virtual reality for reducing experimental ischemic pain. Int. J. Hum. Comput. Int. 15, 469-486. doi:10.1207/S15327590IJHC1503_10

Hoffman, H. G., Patterson, D. R., Magula, J., Carrougher, G. J., Zeltzer, K., Dagadakis, S., et al. (2004). Water-friendly virtual reality pain control during wound care. J. Clin. Psychol. 60, 189-195. doi:10.1002/jclp.10244

Kenny, M. P., and Milling, L. S. (2016). The effectiveness of virtual reality distraction for reducing pain: a meta-analysis. Psychol. Conscious. Theory Res. Pract. 3, 199-210. doi:10.1037/cns0000084

Kizony, R., Katz, N., Rand, D., and Weiss, P. L. (2006). "A Short Feedback Questionnaire (SFQ) to enhance client-centered participation in virtual environments," in Proceedings of 11th Annual Cybertherapy Conference: Virtual Healing: Designing Reality.

Kuhaneck, H. M., Spitzer, S. L., and Miller, E. (2010). Activity Analysis, Creativity, and Playfulness in Pediatric Occupational Therapy. Burlington, MA: Jones \& Bartlett learning.

Kushner, D. (2004). Computing gets physical. Technol. Rev. 107, 57-61.

Law, E. F., Dahlquist, L. M., Sil, S., Weiss, K. E., Herbert, L. J., Wohlheiter, K., et al. (2010). Videogame distraction using virtual reality technology for children experiencing cold pressor pain: the role of cognitive processing. J. Pediatr. Psychol. 36, 84-94. doi:10.1093/jpepsy/jsq063

Legrain, V., Gue'rit, J. M., Bruyer, R., and Plaghki, L. (2002). Attentional modulation of the nociceptive processing into the human brain: selective spatial attention, probability of stimulus occurrence, and target detection effects on laser evoked potentials. Pain 99, 21-39. doi:10.1016/S0304-3959(02)00051-9

Legrain, V., Van Damme, S., Eccleston, C., Davis, K. D., Seminowicz, D. A., and Crombez, G. A. (2009). A neurocognitive model of attention to pain: behavioral and neuroimaging evidence. Pain 144, 230-232. doi:10.1016/j.pain. 2009.03.020

Loreto-Quijada, D., Gutiérrez-Maldonado, J., Nieto, R., Gutiérrez-Martínez, O., Ferrer-García, M., Saldaña, C., et al. (2014). Differential effects of two virtual reality interventions: distraction versus pain control. Cyberpsychol. Behav. Soc. Netw. 17, 353-358. doi:10.1089/cyber.2014.0057
Mahrer, N. E., and Gold, J. I. (2009). The use of virtual reality for pain control: review. Curr. Pain Headache R. 13, 100-109. doi:10.1007/s11916-009-0019-8

McCaul, K. D., and Malott, J. M. (1984). Distraction and coping with pain. Psychol. Bull. 95, 516-533. doi:10.1037/0033-2909.95.3.516

Miron, D., Duncan, G. H., and Bushnell, M. C. (1989). Effects of attention on the intensity and unpleasantness of thermal pain. Pain 39, 345-352. doi:10.1016/0304-3959(89)90048-1

Mulhberger, A., Wieser, M. J., Kenntner-Mabiala, R., Pauli, P., and Wiederhold, B. K. (2007). Pain modulation during drives through cold and hot environments. Cyberpsychol. Behav. 10, 516-522. doi:10.1089/cpb.2007.9996

Murphy, K. R., and Davidshofer, C. O. (1994). Psychological Testing: Principles and Applications, 3rd Edn. Englewood Cliffs, NJ: Prentice Hall.

Oosterman, J. M., Dijkerman, H. C., Kessels, P. C., and Scherder, E. J. A. (2010). A unique association between cognitive inhibition and pain sensitivity in healthy participants. Eur. J. Pain 14, 1046-1050. doi:10.1016/j.ejpain.2010.04.004

Pud, D., Golan, Y., and Pesta, R. (2009). Hand dominancy - a feature affecting sensitivity to pain. Neurosci. Lett. 467, 237-240. doi:10.1016/j.neulet.2009.10.048

Romero, Y. R., Straube, T., Nitsch, A., Miltner, W. H., and Weiss, T. (2013). Interaction between stimulus intensity and perceptual load in the attentional control of pain. Pain 154, 135-140. doi:10.1016/j.pain.2012.10.003

Seminowicz, D. A., and Davis, K. D. (2007). Interactions of pain intensity and cognitive load: the brain stays on task. Cereb. Cortex 17, 1412-1422. doi:10.1093/ cercor/bhl052

Sil, S., Dahlquist, L. M., Thompson, C., Hahn, A., Herbert, L., Wohlheiter, K., et al. (2014). The effects of coping style on virtual reality enhanced videogame distraction in children undergoing cold pressor pain. J. Behav. Med. 37, 156-165. doi:10.1007/s10865-012-9479-0

Solberg Nes, L., Roach, A. R., and Segerstrom, S. C. (2009). Executive functions, self-regulation and chronic pain: a review. Ann. Behav. Med. 37, 173-183. doi:10.1007/s12160-009-9096-5

Sveistrup,H.,McComas, J., Thornton,M.,Marshal,S., Finestone,H.,McCormick,A., et al. (2003). Experimental studies of virtual reality-delivered compared to conventional exercise program for rehabilitation. Cyberpsychol. Behav. 6, 245-249. doi:10.1089/109493103322011524

Thomas, H. (2015). Occupation Based Activity Analysis. Thorofare, NJ: Slack Incorporated.

Van Damme, S., Legrain, V., Vogt, J., and Crombez, G. (2010). Keeping pain in mind: a motivational account of attention to pain. Neurosci. Biobehav. Rev. 32, 204-213. doi:10.1016/j.neubiorev.2009.01.005

Witmer, B. G., and Singer, M. J. (1998). Measuring presence in virtual environments: a presence questionnaire. Presence Teleoperators Virtual Environ. 7, 225-240. doi:10.1162/105474698565686

Yarnitsky, D., Arendt-Nielsen, L., Bouhassira, D., Edwards, R. R., Fillingim, R. B., Granot, M., et al. (2010). Recommendations on terminology and practice of psychophysical DNIC testing. Eur. J. Pain 14, 339. doi:10.1016/j.ejpain.2010.02.004

Conflict of Interest Statement: The authors declare that the research was conducted in the absence of any commercial or financial relationships that could be construed as a potential conflict of interest.

Copyright (c) 2018 Demeter, Pud and Josman. This is an open-access article distributed under the terms of the Creative Commons Attribution License (CC BY). The use, distribution or reproduction in other forums is permitted, provided the original author(s) or licensor are credited and that the original publication in this journal is cited, in accordance with accepted academic practice. No use, distribution or reproduction is permitted which does not comply with these terms. 